九州大学学術情報リポジトリ

Kyushu University Institutional Repository

\title{
Simulation-based 0ptimum Models for Type-I(a) and Type-I(b) IUPAC Classified Adsorption Isotherms
}

Md. Matiar Rahman

Mechanical Engineering Department, Kyushu University

Pal, Animesh

Department of Nuclear Engineering, University of Dhaka

Bidyut Baran Saha

Mechanical Engineering Department, Kyushu University

https://doi.org/10.5109/4102457

出版情報: Proceedings of International Exchange and Innovation Conference on Engineering \& Sciences (IEICES). 6, pp. 14-19, 2020-10-22. Interdisciplinary Graduate School of Engineering Sciences, Kyushu University バージョン:

権利関係 : 


\title{
Simulation-based Optimum Models for Type-I(a) and Type-I(b) IUPAC Classified Adsorption Isotherms
}

\author{
Md. Matiar Rahman ${ }^{1,2,3}$, Animesh $\mathrm{Pal}^{4}$, Bidyut Baran Saha ${ }^{1,2}$ \\ ${ }^{1}$ Mechanical Engineering Department, Kyushu University, 744 Motooka, Nishi-ku, \\ Fukuoka 819-0395, Japan \\ ${ }^{2}$ International Institute for Carbon-Neutral Energy Research (WPI-I2CNER), Kyushu University, 744 Motooka, Nishi- \\ ku, Fukuoka 819-0395, Japan \\ ${ }^{3}$ Department of Statistics, University of Dhaka, Dhaka-1000, Bangladesh \\ ${ }^{4}$ Department of Nuclear Engineering, University of Dhaka, Dhaka-1000, Bangladesh \\ Corresponding author email: saha.baran.bidyut.213@m.kyushu-u.ac.jp
}

\begin{abstract}
Adsorption cooling technologies driven by low-grade thermal or solar power are used as an alternative to refrigeration and air conditioning systems. To boost the calculation of the performance parameters, the replication of experimental data and the rigorous study of adsorption heat transformation (AHT) method, optimum adsorption isotherms model must be identified. Scientists face difficulties in selecting the right isotherm model to explain their experimental observations. This research introduces the optimal models for Type-I(a) and Type-I(b) International Union of Pure and Applied Chemistry (IUPAC) isotherms. This study suggests optimum model based on simulation, where samples were taken using multivariate normal distribution by varying parameters. Firstly, the Box and Whisker error plots identify modified BET and Tóth models corresponding to Type-I(a) and Type-I(b) isotherms. Secondly, the robust parametric ANOVA and pairwise Tukey HSD test confirms that these two models are significantly optimal. The results presented are significant in comprehensive adsorption cycle research.
\end{abstract}

Keywords: ANOVA; isotherm model; IUPAC; optimum isotherm; Tukey HSD

\section{INTRODUCTION}

Due to the growing alarm of deterioration for the ozone layer and global climate change, environmentally efficient cooling technologies have gained a great deal of attention in recent decades [1-3]. Conventional cooling systems use a significant amount of fossil fuels to generate the electricity needed to drive these energyintensive devices. In this context, adsorption-based cooling systems are considered to be very efficient as they can be powered by low-grade thermal energy like waste heat or price efficient, non-concentrating thermal solar collectors [4] with a temperature of as low as $60^{\circ}$ $\mathrm{C}$ [5]. The main component of an adsorption cycle is the adsorption chamber, a heat exchanger that holds the adsorbent materials. Within cycles, the adsorbent material in the chamber is adsorbed and desorbed of the refrigerant to provide thermal compression of the adsorbate.

Hu et al [6] identified the adsorption isotherms at 77 $\mathrm{K}$ for high-resolution $\mathrm{N}_{2}$ adsorption on a K4-700. Cychosz et al. [7] explained at temperature $87 \mathrm{~K}$ for argon adsorption on heteroatom-doped carbons BIDC-X700 adsorbent as a Type-I(a) adsorption behavior. However, they could not determine which model is potentially related to the experimental data. Pal et al. [8] used Langmuir, Tóth and modified Dubinin-Astakhov (D-A) models to investigate the adsorption of $\mathrm{CO}_{2}$ onto composite adsorbents that exhibits Type-I(b) behavior. In another investigation of Type-I(b), Pal et al. [9,10] investigated Langmuir, Freundlich, Tóth, and D-A models for ethanol adsorption on waste palm trunk and mangrove-based activated carbon adsorbents and found that in this case, D-A and Tóth models performed the best. Ibrahim et al. [11] demonstrated that D-A model is the best isotherm model for ethanol adsorption onto
Maxsorb III as a Type-I(b) isotherm. Rahman et al. [12] studied the adsorption of water onto silica gel using statistical analysis for same type and concluded that Toth model is better. Sultan et al. [13] used D-A isotherm model to adsorption water onto zeolite as a Type-I(b) IUPAC classified adsorption isotherm.

Adsorption isotherms gives adsorption capacity of refrigerant materials to find stronger or weaker adsorption processes. The process of adsorption is generally studied by means of isotherm models. Adsorption isotherm is very important for detecting the performance of adsorption cycles. So, optimum adsorption isotherm is very important to identify for rigorous analysis of the efficiency of adsorption cycle. In order to provide an accurate experimental data of various adsorbents-refrigerant pairs, it is necessary to compare them with different isotherm models. The IUPAC [14] categorizes all adsorbent-refrigerant pairs into eight separate types according to the pattern of adsorption and presented in Figure 1.

In our previous research, the optimal models in IUPAC-classified isotherms were determined using statistical method [15]. The isotherm model's parameters were determined using non-linear generalized reduced gradient (GRG) method. For the fitting of the different models, both the numerical significance of the error and the visualization of the fitted graph is considered. For that reason, some tuning has been done to reach optimum value of the parameters. Therefore, there is an infinite number of solutions available in that case. If at the time of optimization one parameter of a model is changed, the other parameters of the same model are automatically changed. And in this situation, attention should be given to the sensitivity or variation of the parameters. On the other hand, the previous research [15] considered 
information criteria to find optimum model. Sometimes information-based criterion selects the model that have more parameters compare to other models. These two drawbacks can be modified considering simulation-based analysis, using parameter variations. This work is simply the improvement of the previous research.

In this paper, two "adsorbent-refrigerant" pairs have been considered to analyze for selecting optimum models corresponding to Type-I(a) and Type-I(b) IUPAC classified adsorption isotherm. The experimental adsorption data have been fitted by possible candidate models employing GRG non-linear optimization methods using root mean square deviation (RMSD) error evaluation function. The R-programming language was used to take $\mathrm{N}=10000$ simulated sample using multivariate normal distribution by varying parameters of standard ranges and RMSD has been calculated each time. Box and Whisker plot of RMSD has been constructed to visualize the five-number summary of the candidate models. Minimum error distribution of the isotherm model indicates better fitted and hence optimum one.

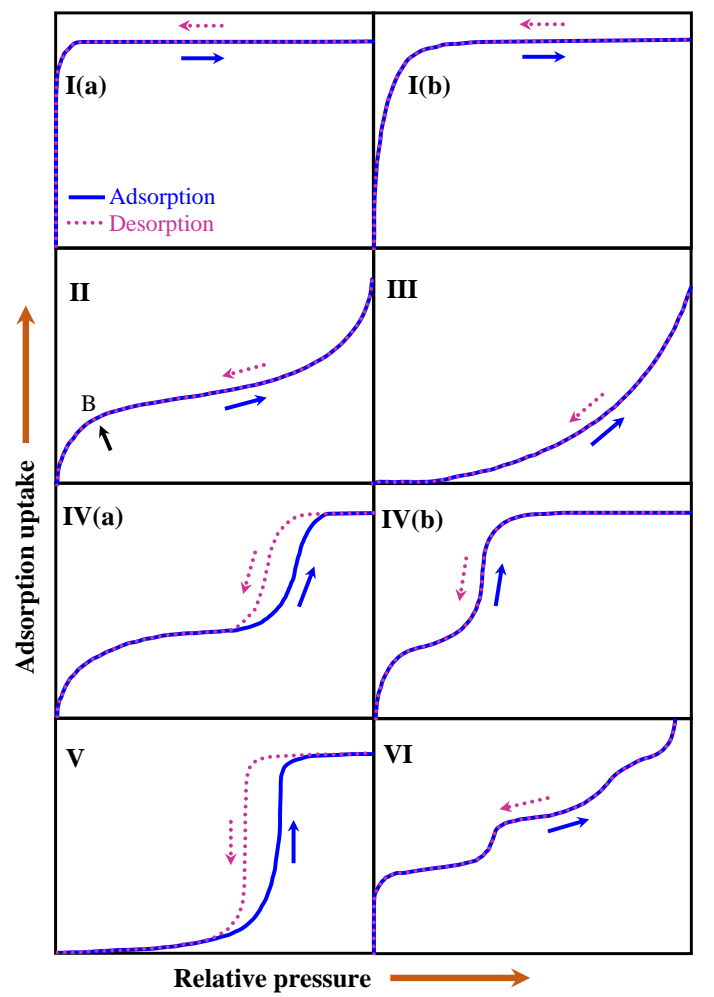

Figure 1 IUPAC classified eight type of adsorption isotherms $[14,15]$.

Robust Parametric test, ANOVA was used to test the and pairwise tests of Tukey HSD were conducted to ensure significantly optimal model.

\section{ADSORPTION ISOTHERM MODELS}

Adsorption isotherm model can explain the absorption of equilibrium uptake at a certain temperature, which shows the different absorption uptake at different equilibrium pressure. Scientists presented different isotherm model to reproduce the adsorption data of different adsorption pairs. The isotherm models of non-linear form with parameters and references are presented in

Table 1 .
Table 1 Isotherm model description with references

\begin{tabular}{|c|c|c|}
\hline Model & Non-linear form & $\begin{array}{l}\text { Parameters } \\
\text { with Ref. }\end{array}$ \\
\hline Freundlich & $\frac{W}{W_{0}}=\left(\frac{P}{P_{s}}\right)^{1 / n}$ & $\begin{array}{l}W_{0}, n \\
{[9,16]}\end{array}$ \\
\hline Langmuir & $\frac{W}{W_{0}}=\frac{b_{0} e^{\frac{Q}{R T}} P}{1+b_{0} e^{\frac{Q}{R T}} P}$ & $\begin{array}{l}W_{o}, Q, b_{o} \\
{[17,18]}\end{array}$ \\
\hline D-A & $\frac{W}{W_{0}}=\exp \left[-\left\{\frac{R T}{E} \ln \left(\frac{P_{s}}{P}\right)\right\}^{n}\right]$ & $\begin{array}{l}W_{0}, E, n \\
{[12,19]}\end{array}$ \\
\hline Mod. D-A & $\begin{array}{c}q_{a b s}^{*}=\frac{W_{0}}{V_{m}} \exp \left[-\left\{\frac{R T}{E} \ln \left(\frac{P_{s}}{P}\right)\right\}^{n}\right] \\
\text { Where, } V_{m}=V_{t} \exp \left[\alpha\left(T-T_{t}\right)\right] \\
\text { And } P_{s}=\left(\frac{T}{T_{c}}\right)^{K} P_{c}\end{array}$ & $\begin{array}{l}W_{0}, E, n, K \\
{[10,20]}\end{array}$ \\
\hline Tóth & $\frac{W}{W_{0}}=\frac{b_{0} e^{\frac{Q}{R T}} \cdot P}{\left[1+\left(b_{0} e^{\frac{Q}{R T}} \cdot P\right)^{t}\right]^{1 / t}}$ & $\begin{array}{l}W_{0}, b 0, Q, t \\
{[21]}\end{array}$ \\
\hline Mahle & $\begin{array}{l}\frac{W}{W_{s}}=\frac{1}{C}\left[\tan ^{-1}\left(\frac{x-A}{B}\right)-\tan ^{-1}\left(\frac{-A}{B}\right)\right] \\
\text { where, } C=\tan ^{-1}\left(\frac{1-A}{B}\right)-\tan ^{-1}\left(\frac{-A}{B}\right) \\
\text { and } A=\exp \left(A_{0}+\frac{A_{1}}{T}\right)\end{array}$ & $\begin{array}{l}W_{s}, A_{0}, A_{l}, \\
B \\
{[22]}\end{array}$ \\
\hline $\begin{array}{l}\text { Modified } \\
\text { BET }\end{array}$ & $\frac{V}{V_{m}}=\frac{C K x}{(1-K x)\{(1+(C-1) K x)\}}$ & $\begin{array}{lll}V_{m}, & C, & K \\
{[17]} & & \end{array}$ \\
\hline Universal & $\begin{array}{l}\frac{q}{q^{*}}=\sum_{i=1}^{n} \alpha_{i}\left[\frac{\left(\frac{p}{p_{s}} \exp \left(\frac{\varepsilon_{o i}}{R T}\right)\right)^{\frac{R T}{m i}}}{1+\left(\frac{p}{p_{s}} \exp \left(\frac{\varepsilon_{o i}}{R T}\right)\right)^{\frac{R T}{m i}}}\right] \\
\text { Where, } \sum_{i=1}^{n} \alpha_{i}=1\end{array}$ & $\begin{array}{l}q^{*}, \quad m_{i}, \alpha_{i}, \\
\varepsilon_{o i} \\
{[23]}\end{array}$ \\
\hline
\end{tabular}

\section{ERROR EVALUATION FUNCTION}

The principle of parameter estimation, such that the error is as small as possible. In this study, the parameters of the model were determined by minimizing the following root mean square deviation (RMSD) [12] of error evaluation function. The error measurement function RMSD can be expressed as-

$$
R M S D=\sqrt{\frac{\sum_{i=1}^{n}\left(W_{\text {exp }}-W_{c a l}\right)_{i}^{2}}{n}}
$$

This error is used to determine the model parameters, preventing significant variance in error between isotherm model and experimental data. RMSD 's error distribution assumes meso-kurtic which is the assumption of least square regression.

\section{SIMULATION ALGORITHM}

We do the simulation method several times and compare the predictive performance of the models based on RSMD's distribution. Given a set of parameters $\theta=\left(\theta_{1}, \theta_{2}, \ldots . ., \theta_{p}\right)$ with the proposed estimates 
$\hat{\theta}=\left(\hat{\theta}_{1}, \hat{\theta}_{2}, \ldots . ., \hat{\theta}_{p}\right)$ which are assumed to have minimum prediction error, the procedure can be stated as follows.

i) Randomly select a vector from $\mathrm{x}=\left(\mathrm{x}_{1}, \mathrm{x}_{2}, \ldots . . \mathrm{x}_{\mathrm{p}}\right)$ from a multivariate normal distribution with mean vector $\hat{\theta}$ and variance-covariance matrix $\Sigma$. We assume that the variances are small $(0.01,0.001$ etc.), i.e., the variability in the choice of estimates from the GRG graph is not substantial.

ii) Obtain the estimated values of the experimental findings by using the predictions chosen and measure the resulting RMSDs.

iii) Repeat i) and (ii) a significant number of times (10000) and compare the model prediction results based on the RSMD 's empirical distributions.

Firstly, Box and Whisker plot was constructed for all candidate models using this simulated $\mathrm{n}=10000$ RMSD. ANOVA test for equality of means of the candidate models was carried out for a specific type and finally, Pairwise Tukey HSD test was conducted to determine the optimum model.

\section{STATISTICAL MEASUREMENT AND TESTS 5.1 The Box and the Whisker plot}

The box and the Whisker plot [24,25] are a chart comprising five concise statistics which are the smallest value (min), 1st quartile $\left(\mathrm{Q}_{1}\right)$, 2nd quartile or median $\left(\mathrm{M}_{\mathrm{e}}\right)$, 3rd quartile $\left(\mathrm{Q}_{3}\right)$, and maximum value (max) of a data set. In this plot, a box is drawn from the first quartile $\left(\mathrm{Q}_{1}\right)$ to third quartile $\left(\mathrm{Q}_{3}\right)$. Median $(\mathrm{Me})$ is a perpendicular line which goes between $\mathrm{Q}_{1}$ and $\mathrm{Q}_{3}$. The whiskers are a line from $\mathrm{Q}_{1}$ to minimum and $\mathrm{Q}_{3}$ to maximum. Total observations are distributed in equal proportion among the four components depicted in Figure 2. Twenty five percent observations are smaller than first quartile $\left(Q_{1}\right)$ and seventy five percent observations are higher than $\mathrm{Q}_{1}$. Similarly, seventy five percent observations are smaller than $\mathrm{Q}_{3}$ and twenty five percent observations are bigger than $\mathrm{Q}_{3}$. The interval $\left(\mathrm{Q}_{1}\right.$, $\mathrm{Q}_{3}$ ) is known as interquartile range which contains 50 percent observations.

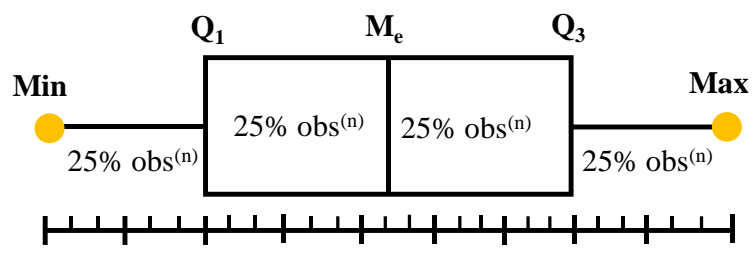

Figure 2 The Box and the Whisker plot.

\subsection{Analysis of variance (ANOVA)}

The Statistician Ronald Fisher developed ANOVA $[24,25]$. In analysis of variance, Total variation in a series of data is divided into various influential factors known as causes of variance and undefined sources of variation known as errors. ANOVA provides equality of several mean tests ( $\mathrm{F}$ test) which is a generalization of $\mathrm{t}$-test for more than two means. The null hypothesis is given by-

$\mathrm{H}_{0}: \mu_{1}=\mu_{2}=\mu_{3} \ldots=\mu_{\mathrm{k}} \mathrm{vs}$

$\mathrm{H}_{1}$ : At least two means are unequal.

Where $\mathrm{k}$ indicates the number of independent groups for comparison. For $\mathrm{k} \geq 2$, it is assumed that $\mathrm{k}$ samples drawn from $\mathrm{k}$ population. The hypothesis is that $\mathrm{k}$ population has the same mean. In ANOVA, total SS is divided into two independent parts which are treatment SS and error SS. $\sum_{i=1}^{k} \sum_{j=1}^{n_{i}}\left(x_{i j}-\bar{x}\right)^{2}=\sum_{i=1}^{k} n_{i}\left(\bar{x}_{i}-\bar{x}\right)^{2}+\sum_{i=1}^{k} \sum_{j=1}^{n_{i}}\left(x_{i j}-\bar{x}_{i}\right)^{2}$

Here, the term $\sum_{i=1}^{k} \sum_{j=1}^{n_{i}}\left(x_{i j}-\bar{x}\right)^{2}$ measures total SS, $\sum_{j=1}^{n_{i}} \sum_{i=1}^{k} n_{i}\left(\bar{x}_{i}-\bar{x}\right)^{2}$ is treatment SS and the last part $\sum_{i=1}^{k} \sum_{j=1}^{n_{i}}\left(x_{i j}-\bar{x}_{i}\right)^{2}$ is error SS.

The F statistic for this test is given by,

$$
F=\frac{\sum_{i=1}^{k} n_{i}\left(\bar{x}_{i}-\bar{x}\right)^{2} /(k-1)}{\sum_{i=1}^{k} \sum_{j=1}^{n_{i}}\left(x_{i j}-\bar{x}_{j}\right)^{2} /(N-1)}
$$

where, $N=n \times k$ and the critical value of F-distribution is found from probability table using $(k-1, N-k)$ degrees of freedom. P-value was determined using F-statistics and the decision was taken by comparison with significance level $\alpha$.

\subsection{Pairwise test (Tukey HSD)}

Tukey's Honest Significant Difference (HSD) test [2426 is a post hoc test usually used to test the significance of differences between pairs of group means. Multiple methods for comparison include the Sheffe test and the Dunnett test. With only two groups of observations we could assess the two group means using a t-test. If we have more than two groups, it's unacceptable to simply compare each pair using a t-test due to various learning issues. The best approach to do the study is to use ANOVA to determine if there is any proof that the populations means differ significantly. The study measures the difference between each pair of instruments with an appropriate modification for multiple tests. Tukey (HSD) test assumes that the observation is normally distributed on the same variations from different groups. Tukey HSD is often a follow up to oneway ANOVA, when the F-test has showed significance difference among groups. HSD can be calculated by using the following formula-

$H S D=\frac{\left(M_{i}-M_{j}\right)}{\sqrt{M S_{\text {within }} / n_{k}}}$; where $\left(M_{i}-M_{j}\right)$ indicates the differences between two means, $M S_{\text {within }}$ measures within mean sum of square value in the ANOVA, $n_{k}$ is the number of samples in $k^{\text {th }}$ group. The critical value is obtained by using Tukey's critical value table.

\section{RESULTS AND DISCUSSION}

Two adsorbent-adsorbate pairs of data have been considered for Type-I(a) and Type-I(b) IUPAC classified adsorption isotherm. Using RMSD error assessment function, GRG non-linear optimization approach was used to optimize model parameters. The Box and whisker plot of the error has been constructed by using 10000 simulated sample. The optimum model has been confirmed by testing two parametric test ANOVA and pairwise Tukey test HSD. 


\subsection{Type-I(a) and Type-I(b) adsorption isotherm}

The IUPAC report 2015 [25] has been suggested two new type which are Type-I(a) and Type-IV(b). Type-I(a) isotherm is observed to have a pore size less than $1 \mathrm{~nm}$ for small microporous adsorbent. For example, adsorption of nitrogen gas onto the adsorbent K4-700 at $77 \mathrm{~K}$ [6] demonstrated this type of isotherm. The adsorption isotherm of Type-I(b) is mainly described by monolayer adsorption. The absorption increases steadily with pressure and approaches a peak under saturation pressure. The maximum uptake is measured by the sufficient micropore volume.

\subsection{Simulation based error analysis and model selection}

$\mathrm{Hu}$ et al. [6] measured the adsorption isotherms at $77 \mathrm{~K}$ for adsorption of high-resolution $\mathrm{N}_{2}$ onto a K4-700. These isotherms are fitted with Tóth, D-A, Mod-BET, Universal, and Mahle model in the current study and presented in Figure 3(a). Pal et al. [8] analyzed the adsorption of $\mathrm{CO}_{2}$ gas onto carbon-based composites by taking three temperatures of $30^{\circ} \mathrm{C}, 50^{\circ} \mathrm{C}$ and $70{ }^{\circ} \mathrm{C}$. The experimental data have been fitted with five probable isotherm models and graphical representation of their fittings are depicted in Figure 3(b). The estimated parameters are presented in Table 2.
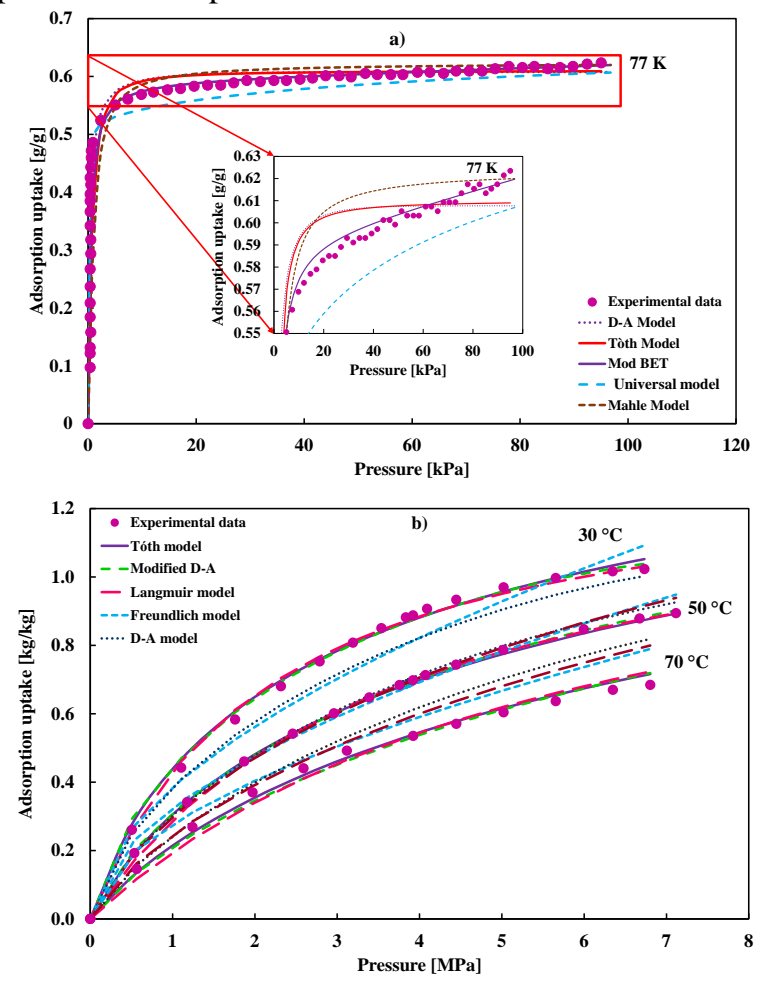

Figure 3 Type-I(a) for K4-700/ $\mathrm{N}_{2}$ and Type-I(b) for carbon-based composite/ $\mathrm{CO}_{2}$ pairs are presented in (a) and (b) respectively. (data are fitted with probable isotherm models using RMSD error function).

Table 2 Fitting parameters of the candidate models.

\begin{tabular}{ll}
\hline \multicolumn{1}{c}{ Model } & \multicolumn{1}{c}{ Type-I(a) } \\
\hline Mahle & $\mathrm{W}_{0}=0.62, \mathrm{~A}_{0}=0.045, \mathrm{~A}_{1}=-720, \mathrm{~B}=0.01$ \\
Universal & $\mathrm{W}_{0}=0.709, \varepsilon_{01}=4120, \varepsilon_{0}=0.0345, \mathrm{~m}_{1}=320$, \\
& $\mathrm{m}_{2}=1000, \alpha_{1}=0.71, \alpha_{2}=0.29$ \\
D-A & $\mathrm{W}_{0}=0.607, \mathrm{E}=320, \mathrm{n}=3.31$ \\
Tóth & $\mathrm{W}_{0}=0.61, \mathrm{~b} 0=9.79 \mathrm{E}-05, \mathrm{Q}=6013.84, \mathrm{t}=1.3$ \\
Mod BET & $\mathrm{V}_{\mathrm{m}}=0.594, \mathrm{C}=5334.78, \mathrm{k}=0.0446$ \\
& Type- $\mathrm{I}(\mathbf{b})$ \\
\hline \hline
\end{tabular}

\begin{tabular}{ll}
\hline \hline Freundlich & $\mathrm{W}_{0}=1.13436, \mathrm{n}=1.82886$ \\
Langmuir & $\mathrm{W}_{0}=1.3613, \mathrm{~b}=7.19 \mathrm{E}-05, \mathrm{Q}=22105.7982$ \\
$\mathrm{D}-\mathrm{A}$ & $\mathrm{W}_{0}=1.071, \mathrm{E}=115.635, \mathrm{n}=1.254$ \\
Tóth & $\mathrm{W}_{0}=1.74, \mathrm{~b}=7.7 \mathrm{E}-5, \mathrm{Q}=22062.63, \mathrm{t}=0.7084$ \\
Mod D-A & $\mathrm{W}_{0}=1.104, \mathrm{E}=126.570, \mathrm{n}=1.326, \mathrm{k}=5.506$ \\
\hline \hline
\end{tabular}

\subsection{Box and whisker plot:}
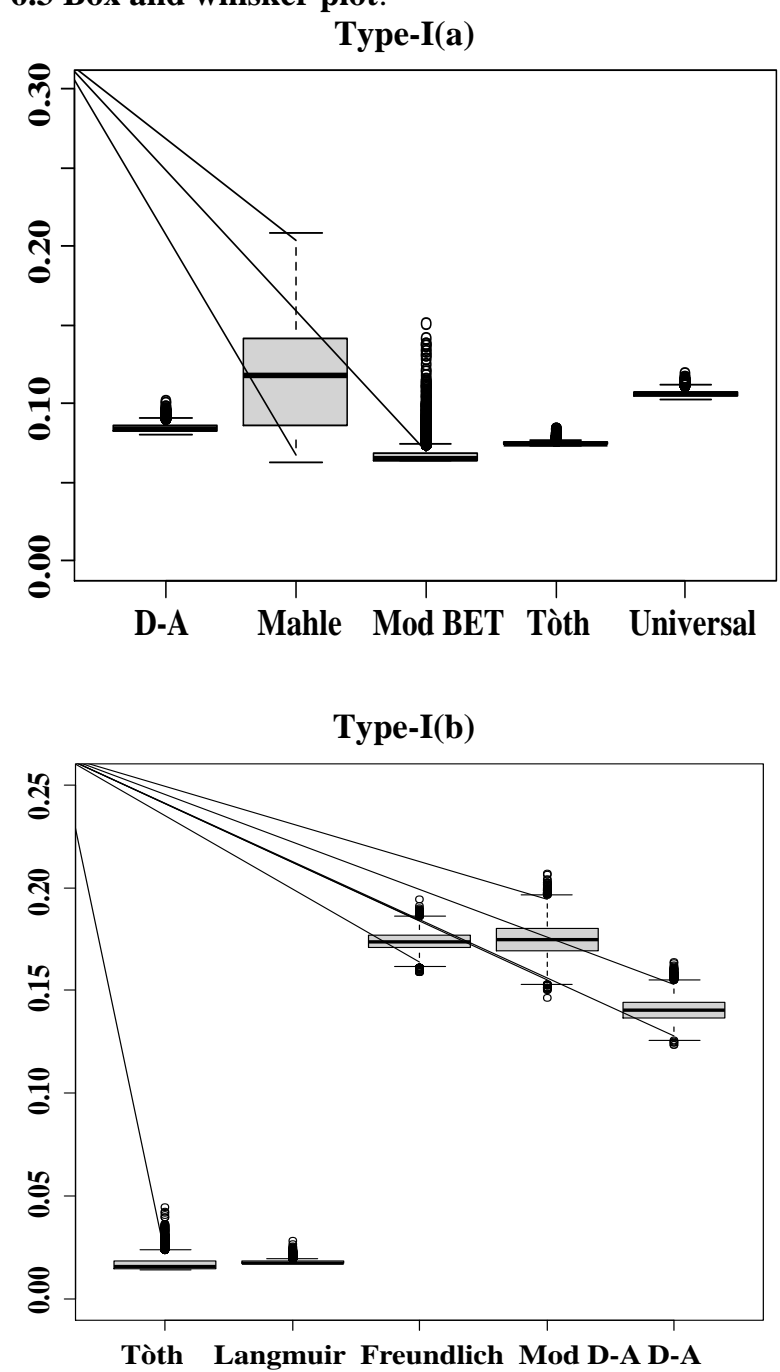

Figure 4 Box and whisker plot of the RMSD error mean for $\mathrm{N}=10000$ simulated data set for Type-I(a) and TypeI(b) adsorption isotherms.

From Figure 4, it is observed that the box plot of modified BET model placed in the lower of the figure for TypeI(a) compare to other four candidate models which indicates modified BET models have lower five number summary (minimum, 1st quartile, median, 3rd quartile, maximum) than other models. It is observed that the box plot of Tóth and Langmuir model placed in the lower of the figure for Type-I(b) compare to Freundlich, Modified DA and DA models which indicates Tóth and Langmuir models have lower five statistics (minimum, $1^{\text {st }}$ quartile, median, $3^{\text {rd }}$ quartile, maximum) than other three models. Tóth model shows slightly better than Langmuir model. This finding validates the results of our previous study.

\subsection{Analysis of variance (ANOVA)}

ANOVA test results have been reported in Table 3 for Type-I(a) and Type-I(b) IUPAC classified adsorption isotherm including mean square sum (Mean SS), F-value, and P-values. 
Table 3 ANOVA results for Type-I(a) and Type-I(b)

\begin{tabular}{llll}
\hline \hline Factor (model) & Mean SS & F-value & P-value \\
\hline Type-I(a) & 6.308 & 8452 & $<2.1 \mathrm{E}-16$ \\
Type-I(b) & 65.43 & 2532683 & $<2.3 \mathrm{E}-14$ \\
\hline \hline
\end{tabular}

In these results, the null hypothesis states that the average RMSD of five candidate isotherm models are equal. The p-value is less than the level of significance 0.01 for both types, so, we can reject the null hypothesis and conclude that some models have significantly different RMSD. It is notable that the larger mean SS of Type-I(b) relative to Type-I(a) suggests that the Type-I(b) candidate models are not all well fitted. Rejection of ANOVA test hypothesis means that all candidate models RMSD are not equivalent for their respective types. In order to find the best fitted isotherm model pairwise Tukey HSD needs to perform and the results of this pairwise test have been shown in Table 4.

\subsection{Pairwise test: Tukey HSD test}

In Table 4, pairwise comparison of Tukey HSD test results for Type-I(a) and Type-I(b) isotherms including model differences, mean RMSD differences and P-values is shown.

Table 4 Pairwise test: Tukey HSD test

\begin{tabular}{ccc}
\hline \multicolumn{3}{c}{ Type-I(a) } \\
RMSD mean & P-value \\
& differences & \\
\hline Mahle-DA & 0.057413 & $2.1 \mathrm{E}-12$ \\
Mod BET -DA & -0.011417 & $1.8 \mathrm{E}-15$ \\
Tóth -DA & -0.000469 & $\mathbf{0 . 7 4 3 1}$ \\
Universal -DA & -0.001098 & 0.0360 \\
Mod BET-Mahle & -0.045996 & $1.2 \mathrm{E}-05$ \\
Tóth -Mahle & -0.057882 & $3.1 \mathrm{E}-04$ \\
Universal-Mahle & -0.058512 & $2.9 \mathrm{E}-07$ \\
Tóth -Mod BET & $\mathbf{0 . 0 1 1 8 8 6}$ & $\mathbf{1 . 6 E - 0 9}$ \\
Universal-Mod BET & 0.012516 & $2.2 \mathrm{E}-11$ \\
Universal- Tóth & 0.000629 & $\mathbf{0 . 4 7 8 3}$ \\
& Type-I(b) & \\
Langmuir-Tóth & $\mathbf{0 . 0 0 0 7 9 8}$ & $\mathbf{1 . 3 E - 1 1}$ \\
Freundlich-Tóth & 0.156673 & $2.3 \mathrm{E}-13$ \\
Mod DA-Tóth & 0.157599 & 0.00021 \\
DA-Tóth & 0.123551 & 0.00032 \\
Freundlich-Langmuir & 0.155875 & $2.5 \mathrm{E}-08$ \\
Mod DA-Langmuir & 0.156801 & $4.2 \mathrm{E}-05$ \\
DA-Langmuir & 0.122753 & $2.3 \mathrm{E}-06$ \\
Mod DA-Freundlich & 0.000925 & $1.8 \mathrm{E}-06$ \\
DA-Freundlich & -0.033122 & $3.2 \mathrm{E}-13$ \\
DA-Mod DA & -0.034047 & $2.6 \mathrm{E}-08$ \\
\hline \hline
\end{tabular}

The null hypothesis of a Tukey HSD test notes that every pair of models has the same RMSD suggesting discrepancies is negligible. It is found that the pairs TóthDA, Universal-Tóth for Type-I(a) are insignificant based on the results of all possible pair comparison tests of the candidate models. Comparisons from Type-I(a) box and whisker plot shows that Modified BET model is in lower place followed by Toth model. In Tukey's pairwise test shows that the discrepancy between Toth and modified BET is positive and statistically significant suggests that the modified BET model has considerably small RMSD. Modified BET model is the optimal isotherm model for Type I(a) adsorption isotherm. On the other hand, it is obvious from the box and whisker plot for Type-I(b) adsorption isotherm that Tóth and Langmuir model were the possibly optimum model. In the Tukey's pairwise HSD test shows that the differences of RMSD is positive and statistically significant which means Tóth model has significantly small error. Therefore, it is evident based on the pairwise test that Mod BET for Type-I(a) and Tóth for Type-I(b) are significantly low RMSD indicates the optimal model for the respective types.

\section{CONCLUSIONS}

In this research, two appropriate adsorption pairs K4$700 / \mathrm{N} 2$ and carbon-based composite/CO2 related to Type-I(a) and Type-I(b) of IUPAC classified adsorption isotherms are considered for analysis. Selected pairs of adsorptions possess the same properties and curve patterns as their respective types. The non-linear optimization technique GRG has been used to optimize the parameters of the candidate isotherm models. The findings of this analysis provide a powerful insight into which model is suitable for a specific type of adsorption isotherms. $\mathrm{N}=10000$ simulated sample was taken using multivariate normal distribution by varying parameters of standard ranges. Firstly, box and whiskers plots of the error identify modified BET and Tóth models corresponding to Type-I(a) and Type-I(b) with lower error distribution relative to other models. Secondly, the parametric test ANOVA and pairwise Tukey HSD test confirms these two models is significantly optimum for Type-I(a) and Type-I(b) adsorption isotherms.

\section{REFERENCE}

[1] J.M. Calm, Emissions and environmental impacts from air-conditioning and refrigeration systems, Int. J. Refrig. 25 (2002) 293-305.

[2] A. Pal, S. Mitra, K. Thu, B.B. Saha, Improved adsorption uptake of ethanol and $\mathrm{CO} 2$ onto biomass based activated carbons, Proc. Int. Exch. Innov. Conf. Eng. Sci. 3 (2017) 127-128.

[3] M. Muttakin, A. Pal, K. Uddin, K. Thu, K. Ito, B. Baran Saha, Experimental study of CO_2 adsorption kinetics onto activated carbon Experimental study of $\mathrm{CO} 2$ adsorption kinetics onto activated carbon, 4 (2018) 2018-2028.

[4] A.K. Jaiswal, S. Mitra, P. Dutta, K. Srinivasan, S. Srinivasa Murthy, Influence of cycle time and collector area on solar driven adsorption chillers, Sol. Energy. 136 (2016) 450-459.

[5] A. Islam, K.A. Rocky, A. Pal, K. Thu, B.B. Saha, Specific heat capacity measurement of mangrove and waste palm trunk in raw , carbonized and activated form, Fifth Int. Symp. Innov. Mater. Process. Energy Syst. IMPRESS2019. (2019) 151-152.

[6] X. Hu, M. Radosz, K.A. Cychosz, M. Thommes, CO2-Filling Capacity and Selectivity of Carbon Nanopores: Synthesis, Texture, and Pore-Size Distribution from Quenched-Solid Density Functional Theory (QSDFT), Environ. Sci. Technol. 45 (2011) 7068-7074.

[7] K.A. Cychosz, M. Thommes, Progress in the Physisorption Characterization of Nanoporous Gas Storage Materials, Engineering. 4 (2018) 559-566.

[8] A. Pal, I.I. El-Sharkawy, B.B. Saha, S. Jribi, T. 
Miyazaki, S. Koyama, Experimental investigation of $\mathrm{CO} 2$ adsorption onto a carbon based consolidated composite adsorbent for adsorption cooling application, Appl. Therm. Eng. 109 (2016) 304-311.

[9] A. Pal, K. Thu, S. Mitra, I.I. El-Sharkawy, B.B Saha, H.S. Kil, S.H. Yoon, J. Miyawaki, Study on biomass derived activated carbons for adsorptive heat pump application, Int. J. Heat Mass Transf. 110 (2017) 7-19.

[10] A. Pal, K. Uddin, K.A. Rocky, K. Thu, B.B. Saha, CO2 adsorption onto activated carbongraphene composite for cooling applications, Int. J. Refrig. (2019).

[11] I.I. El-Sharkawy, K. Uddin, T. Miyazaki, B.B. Saha, S. Koyama, J. Miyawaki, S.-H.H. Yoon, Adsorption of ethanol onto parent and surface treated activated carbon powders, Int. J. Heat Mass Transf. 73 (2014) 445-455.

[12] M.M. Rahman, A. Pal, K. Uddin, K. Thu, B.B. Saha, Statistical Analysis of Optimized Isotherm Model for Maxsorb III/Ethanol and Silica Gel/Water Pairs, Evergreen. 5 (2018) 1-

[13] M. Sultan, T. Miyazaki, S. Koyama, Optimization of adsorption isotherm types for desiccant air-conditioning applications, Renew. Energy. 121 (2018) 441-450.

[14] M. Thommes, K. Kaneko, A. V. Neimark, J.P. Olivier, F. Rodriguez-Reinoso, J. Rouquerol, K.S.W. Sing, Physisorption of gases, with special reference to the evaluation of surface area and pore size distribution (IUPAC Technical Report), Pure Appl. Chem. 87 (2015) 1051-1069.

[15] M.M. Rahman, M. Muttakin, A. Pal, A.Z. Shafiullah, B.B. Saha, A Statistical Approach to Determine Optimal Models for IUPACClassified Adsorption Isotherms, Energies. 12 (2019) 4565.

[16] B. Wanassi, I. Ben Hariz, C.M. Ghimbeu, C. Vaulot, M. Jeguirim, Green carbon compositederived polymer resin and waste cotton fibers for the removal of alizarin red $\mathrm{S}$ dye, Energies. 10 (2017).

[17] D.D. Do, Adsorption Analysis: Equilibria and Kinetics: (With CD Containing Computer Matlab Programs), 1998.

[18] Z. Liu, Z. Zhang, X. Liu, T. Wu, X. Du, Supercritical CO2 Exposure-Induced Surface Property, Pore Structure, and Adsorption Capacity Alterations in Various Rank Coals, Energies. 12 (2019) 3294.

[19] V.A. Astakhov, M.M. Dubinin, Development of the concept of volume filling of micropores in the adsorption of gases and vapors by microporous adsorbents - Communication 3. Zeolites with large cavities and a substantial number of adsorption centers, Bull. Acad. Sci. USSR Div. Chem. Sci. 20 (1971) 13-16.

[20] K.A.G. Amankwah, J.A. Schwarz, A modified approach for estimating pseudo-vapor pressures in the application of the Dubinin-Astakhov equation, Carbon N. Y. 33 (1995) 1313-1319.

[21] K.A. Rocky, A. Pal, M. Moniruzzaman, B.B. Saha, Adsorption characteristics and thermodynamic property fields of polymerized ionic liquid and polyvinyl alcohol based composite/CO2 pairs, J. Mol. Liq. 294 (2019) 111555.

[22] J.J. Mahle, An adsorption equilibrium model for Type 5 isotherms, Carbon N. Y. 40 (2002) 2753-2759.

[23] K.C. Ng, M. Burhan, M.W. Shahzad, A. Bin Ismail, A Universal Isotherm Model to Capture Adsorption Uptake and Energy Distribution of Porous Heterogeneous Surface, Sci. Rep. 7 (2017) 1-11.

[24] S.B. Vardeman, R.E. Walpole, R.H. Myers, I. Miller, J.E. Freund, Probability and Statistics for Engineers and Scientists.Probability and Statistics for Engineers., 1986.

[25] R. V. Hogg, E.A. Tanis, D.L. Zimmerman, Probability and Statistical Interference, Pearson Education, Inc, USA, 2003.

[26] S.K. Saha, M.E. Haque, D. Islam, M.M. Rahman, M.R. Islam, A. Parvin, S. Rahman, Comparative study between the effect of Momordica charantia (wild and hybrid variety) on hypoglycemic and hypolipidemic activity of alloxan induced type 2 diabetic long-evans rats, J. Diabetes Mellit. 02 (2012) 131-137. 